\title{
ÁRVORES NATIVAS PARA A ARBORIZAÇÃO DE TERESINA, PIAUÍ
}

Roselis Ribeiro Barbosa Machado ${ }^{1}$, Isabelle Maria Jacqueline Meunier ${ }^{2}$, José Antônio Aleixo da Silva ${ }^{3}$, Antônio Alberto Jorge Farias Castro ${ }^{4}$

\section{RESUMO}

O objetivo deste trabalho foi identificar espécies nativas ocorrentes na arborização urbana de Teresina, Piauí, catalogando as informações botânicas e paisagísticas sobre algumas delas. Foram feitas coletas mensais de material botânico das espécies nativas encontradas em parques e praças da cidade, sendo observadas 48 espécies de árvores nativas, distribuídas em 42 gêneros e 21 famílias botânicas. A família de maior representatividade foi Caesalpiniaceae, com 6 gêneros e 7 espécies. Dentre as espécies analisadas, 10 foram consideradas com grandes potencialidades para a arborização da cidade e foram particularmente estudadas, a partir de avaliações visuais e informações da bibliografia técnico-científica especializada. Foram elas: Cenostigma macrophyllum (caneleiro) e Caesalpinia ferrea var. ferrea (jucá), indicadas para praças, canteiros centrais com mais de 4,0m de largura, jardins públicos e estacionamentos; Anadenanthera macrocarpa (angico preto), Licania tomentosa (oiti), Enterolobium contorsiliquum (tamboril), Parkia platycephala (faveira), Astronium fraxinifolium (gonçalo-alves) e Hymenea courbaril (jatobá) para praças e parques, Copernicia prunifera (carnaúba), para canteiros centrais e composições em praças e jardins e Magonia glabrata (tingui), uma sapindácea de porte médio, que deve ser testada na arborização de passeios. Verificou-se a necessidade de maior divulgação das espécies nativas com potencial para uso nas várias modalidades de arborização da cidade, considerando que muitas das espécies avaliadas como potenciais não foram freqüentes nos levantamentos realizados ou foram encontradas em locais inadequados.

Palavras-chaves: Flora nativa, arborização urbana, Teresina.

\footnotetext{
${ }^{1}$ Bióloga, Mestre em Botânica, Doutoranda em Geografia, Departamento de Ciências Biológicas - UESPI / SEMPLAN - PMT, Teresina, Piauí, roselis.machado@ig.com.br

2 Engenheira Florestal MSc., Departamento de Ciência Florestal - UFRPE, Recife, Pernambuco, meunier@hotlink.com.br

3 Engenheiro Florestal Dr., Departamento de Ciência Florestal - UFRPE, Recife, Pernambuco. aleixo@elogica.com.br

${ }^{4}$ Biólogo Dr., Departamento de Biologia - UFPI, Teresina, Piauí, roselis.machado@ig.com.br
} 


\title{
NATIVE TREES FOR THE ARBORIZATION OF TERESINA, PIAUÍ
}

\begin{abstract}
The objective of this work was to identify to ocorrentes native species in the urban arborization of Teresina, Piauí, cataloguing the botanical and paisagísticas information on some of them. Monthly collections of botanical material of the native species found in parks and squares of the city had been made, being observed 48 species of native trees, distributed in 42 sorts and 21 botanical families. The family of bigger representation was Caesalpiniaceae, with 6 sorts and 7 species. Amongst the analyzed species, 10 had been considered with great potentialities for the arborization of the city and particularly had been studied, from visual evaluations and information of the specialized technician-scientific bibliography. They had been they: Cenostigma macrophyllum (caneleiro) and Caesalpinia ferrea var. ferrea (jucá), indicated for public estacionamentos and squares, seedbeds central offices with more than 4,0m of width, gardens; Anadenanthera macrocarpa (angico black), Licania tomentosa (oiti), Enterolobium contorsiliquum (tamboril), Parkia platycephala (faveira), Astronium fraxinifolium (gonçalo-alves) and Hymenea courbaril (jatobá) for squares and parks, Copernicia prunifera (carnaúba), for seedbeds central offices and compositions in squares and gardens and Magonia glabrata (tingui), a sapindácea of average transport, that must be tested in the arborization of strolls. It was verified necessity of bigger spreading of the native species with potential for use in the some modalities of arborization of the city, considering that many of the evaluated species as potential they had not been frequent in the carried through surveys or had been found in inadequate places.
\end{abstract}

Key-words: Native flora, urban arborization, Teresina. 


\section{INTRODUÇÃO}

$\mathrm{Na}$ arborização de cidades brasileiras observa-se uma crescente substituição da flora nativa por plantas exóticas, alterando o ambiente natural que resta nos centros urbanos. Este procedimento uniformiza as paisagens de diferentes cidades e contribui para a redução da biodiversidade no meio urbano, dissociando-o do contexto ambiental onde se insere.

O emprego de espécies da vegetação nativa na arborização de parques, praças, jardins e passeios urbanos parece ser uma prática desejável, com importantes ganhos ambientais, estéticos e culturais para as cidades. Segundo GOYA (1994), as árvores são referências marcantes que se possui de uma cidade e substituí-las é despir o local de parte de sua memória, mudando significantemente sua imagem. Este mesmo autor lembrou que as árvores de cada cidade são parte integrante da memória urbana, sem a qual não se pode vislumbrar o futuro.

A cidade de Teresina, capital do Piauí, não se distancia muito da situação nacional, com o predomínio de espécies exóticas na arborização de passeios das vias públicas (MACHADO, 2001), mas, por outro lado, conta com importantes iniciativas para preservar a flora nativa em praças e parques urbanos, resguardando um pouco de sua história e procurando o convívio harmonioso do homem com os elementos da natureza.

Este trabalho, desenvolvido em Teresina, Piauí, teve como objetivo avaliar a participação das árvores nativas no ambiente urbano, identificando e relacionando as espécies nativas encontradas e associando informações botânicas e paisagísticas daquelas consideradas com potencial para o uso em arborização urbana, de forma a oferecer novas opções de utilização para estas árvores, levando em conta suas qualidades e limitações.

\section{MATERIAIS E MÉTODOS}

O município de Teresina está localizado à margem direita do Rio Parnaíba, ao lado do município maranhense de Timom, a $05^{\circ} 05^{\prime} 12^{\prime \prime}$ de latitude sul e $42^{\circ} 48^{\prime} 42^{\prime \prime}$ de longitude oeste. Apresenta clima Aw, tropical e chuvoso (megatérmico) de savana, com inverno seco e verão chuvoso, com precipitação mensal média de $1.339 \mathrm{~mm}$, temperatura do ar de $26,8^{\circ} \mathrm{C}$ e umidade relativa do ar $70 \%$ (TERESINA, 1993). A paisagem natural é caracterizada por uma cobertura arbustiva de médio porte e densa, com babaçuais e os carnaubais nativos que se estendem preferencialmente ao longo dos vales e terrenos quaternários de maior fertilidade. O cerrado e o cerradão constituem a forma mais comum de vegetação (TERESINA, 1993).

Dentro da área urbana de Teresina localizam-se 22 reservas, denominadas "parques ambientais", que juntos constituem uma área verde de 357,5 ha. Nestes parques encontra- 
se uma grande diversidade de árvores nativas. Também nas praças, segundo MACHADO (2001), a presença de espécies nativas é preponderante. Nesses locais foram realizadas coletas mensais de material botânico das espécies nativas encontradas, modo a acompanhar as florações durante todo ano. Foram preparadas exsicatas com o material coletado e as identificações foram realizadas no Herbário Graziela Barroso, Universidade Federal do Piauí. Reuniram-se informações botânico-dendrológicas e paisagísticas sobre as principais espécies, a partir de observações visuais e de consulta a bibliografia técnica especializada (LORENZI, 1992; LORENZI, 1998), avaliando, em função das características, seus potenciais usos na arorização urbana.

\section{RESULTADOS E DISCUSSÃO}

Ao todo foram observadas 48 espécies de plantas nativas distribuídas em 42 gêneros e 21 famílias botânicas. A família com maior representatividade foi a Caesalpiniaceae, com seis gêneros, seguida de Mimosaceae e Arecaceae (Tabela 1).

Tabela 1. Famílias botânicas, número de gêneros e espécies nativas amostradas na arborização urbana de Teresina, PI.

\begin{tabular}{lcc}
\hline \multicolumn{1}{c}{ FAMÍLIAS } & No DE GÊNEROS & No DE ESPÉCIES \\
\hline Caesalpiniaceae & 6 & 7 \\
Mimosaceae & 5 & 6 \\
Arecaceae & 5 & 5 \\
Anacardiaceae & 3 & 4 \\
Bignoniaceae & 2 & 4 \\
Sapindaceae & 2 & 2 \\
Combretaceae & 2 & 2 \\
Chrysobalanaceae & 2 & 2 \\
Fabaceae & 2 & 2 \\
Moraceae & 2 & 2 \\
Myrtaceae & 1 & 1 \\
Rhamnaceae & 1 & 1 \\
Dilleniaceae & 1 & 1 \\
Malpighiaceae & 1 & 2 \\
Verbenaceae & 1 & 1 \\
Cecropiaceae & 1 & 1 \\
Coclospermaceae & 1 & 1 \\
Meliaceae & 1 & 1 \\
Apocynaceae & 1 & 1 \\
Tiliaceae & 1 & 1 \\
Lecythidaceae & 1 & 1 \\
\hline TOTAIS & 42 & 48 \\
\hline & &
\end{tabular}

Dentre as espécies amostradas, as dez consideradas de maior potencial para a arborização e mais ligadas aos aspectos históricos-culturais da cidade estão relacionadas a seguir, com recomendações para uso em arborização. 


\section{Cenostigma macrophyllum Tul. (Caneleiro) - Caesalpiniaceae}

Árvore com porte de 6 a $16 \mathrm{~m}$, podendo atingir até $20 \mathrm{~m}$, quando nas matas; possui tronco bastante sulcado, ereto e cilíndrico, dotado de copa piramidal, fechada, bastante ramificada e ampla. Casca com manchas cinzentas claras alternadas com escuras. Folhas alternas, compostas, pinadas, paripenadas com folíolos opostos coriáceos. Flores reunidas em inflorescências. O Fruto é um legume lenhoso, deiscente, achatado, glabro, contendo 2 a 4 sementes.

Floração e folhagem bastante atrativas. Flores bem visíveis e numerosas, distribuídas por toda a copa, de cor amarela, bem contrastante com o verde intenso da folhagem. Copa bem distribuída, fechada, dando sombra aprazível. Recomendada para canteiros centrais largos (acima de $4,0 \mathrm{~m}$ de largura), em praças, jardins e para sombreamento de estacionamentos.

\section{Anadenanthera macrocarpa (Benth) Brenam (Angico preto) - Mimosaceae}

Árvore com porte de 13 a 20 m com tronco reto e copa bastante aberta e esgalhada. Casca com espessura de até $30 \mathrm{~mm}$, externamente acinzentadada, de aspecto gretado e escuro. Folhas compostas, bipinadas com folíolos opostos. Flores hermafroditas, esbranquiçadas, pequenas, reunidas em capítulos globosos. Fruto folículo, achatado, coriáceo, castanho-avermelhado, com superfície rugosa. Cada fruto contem de 8 a 15 sementes, castanho a pardo-avermelhadas escuras, brilhantes, arredondadas, achatadas, sem asas, com cerca de $2 \mathrm{~cm}$ de comprimento.

Árvore elegante, com fuste elevado, copa ampla, alta, com certa transparência. Flores e frutos pequenos, destituídos de viscosidade. Recomendada para arborização de praças e parques.

\section{Copernicia prunifera (Miller) H. E. Moore (Carnaúba)}

Arecaceae Palmeira com porte de 10 a 20 m, estipe indiviso, um tanto espessado na base. Copa alta e reduzida a tufos de folhas. $\mathrm{Na}$ base do caule ficam vestígios do pecíolo da folha. As folhas, longamente pecioladas (com pecíolo espinhoso), aglomeram-se em fronde terminal globulosa, apresentando cerca de $1 \mathrm{~m}$ de comprimento. Flores numerosíssimas, hermafroditas pequenas, campanuladas, dispostas em espádice paniculada com até $2 \mathrm{~m}$ de comprimento, protegida por espata tubulosa, seca, membranácea. O fruto é uma drupa arredondada de $2 \mathrm{~cm}$ de comprimento, amarelo-esverdeado tornando-se roxo quando maduro, reunidas em grandes cachos pendentes.

Copa alta, com estipe linheiro, resistente a ação mecânica e pragas, com excelentes adaptações as condições climáticas locais. Recomendado o uso da carnaúba isolada em canteiros centrais com $2 \mathrm{~m}$ de largura e em composições em praças e jardins. 


\section{Caesalpinia ferrea var. ferrea Mart. ex Tul.(Jucá)}

Caesalpiniaceae Árvore com porte de 10 a $20 \mathrm{~m}$, tronco curto de $40-60 \mathrm{~cm}$ de diâmetro e com bifurcações quando isolada. Copa arredondada, fechada, densa. Casca externamente acinzentada, lisa e fina, com manchas brancas irregulares, que contrastam com o fundo escuro do tronco, proporcionando belo efeito decorativo; a casca se renova anualmente; internamente é amarela clara, escurecendo em contato com o ar. Folhas compostas, bipinadas. Flores amarelas e brilhantes, pequenas, reunidas em panícula terminal de até $20 \mathrm{~cm}$ de comprimento. Fruto legume bacóide preto-avermelhado, indeiscente, chato, que ao amadurecer torna-se negro e chocalhante, porque as sementes se soltam dentro de cada lóculo na vagem. Cada fruto contem 2 a 10 sementes elipsóides, amarelas ou marrons e duríssimas.

Copa bem distribuída, ampla, flores e frutos pequenos, leves. Tronco com atrativo espedial pela beleza da casca e resistente à ação mecânica. Crescimento lento a partir de 5 a $7 \mathrm{~m}$. É recomendada para arborização de praças, parques, canteiros centrais de vias públicas e estacionamentos.

\section{Licania tomentosa (Benth.) Fristsh (Oiti) - Chrysobalanaceae}

Árvore com porte de 15 a $20 \mathrm{~m}$, com tronco de 30 a $50 \mathrm{~cm}$ de diâmetro. Copa fechada, arredondada, com folhagem densa. Casca com algumas fissuras e pequena descamação. Folhas simples, alternas, elípticas-lanceoladas, com face abaxial aveludada. Flores pequenas, brancas, com espigas ramosas. Fruto drupáceo, fusiforme ou oval, de 12 a $16 \mathrm{~cm}$ de comprimento, envolto em massa amarela, pegajosa e fibrosa, de cheiro um tanto desagradável, com casca amarela quando maduro, muito procurado pela fauna em geral.

Árvore com fuste bem definido, copa fechada, com folhagem densa, conferindo-lhe excelente sombra. Flores pequenas, frutos atrativos para a fauna. Recomenda-se para arborização de praças e parques.

\section{Enterolobium contortisiliquum (Vell.) Morong (Tamboril) - Mimosaceae}

Árvore com porte de 20 a $30 \mathrm{~m}$, com tronco reto ou pouco tortuoso, cilíndrico, de $80 \mathrm{a}$ $160 \mathrm{~cm}$ de diâmetro. Copa ampla, arredondada, com folhagem mais densa nas extremidades. Casca pardo-acinzentada lisa, pontilhada por abundantes lenticelas grandes $(1 \mathrm{~cm})$ ou escassamente fissurada. Folhas compostas, bipinadas, alternas. Flores hermafroditas, brancas ou cremes, em capítulo globoso contendo 10 a 20 flores e estames numerosos. Fruto legume, bacóide, indeiscente, preto quando maduro, recurvado, semilenhoso, possuindo forma característica que faz lembrar uma orelha humana, profundamente reentrante junto ao pedicelo; polpa amarelo-clara, macia e viscosa; contem 2 a 12 sementes elipsóides, com tegumento liso e duro, marrom brilhante. Raiz superficial. 
Copa alta, ampla, aberta, com folhagem densa de bela coloração (verde claro). Tronco resistente e fruto leve. Recomendada para arborização de praças e parques.

\section{Parkia platycephala Benth. (Faveira) - Mimosaceae}

Árvore com porte de 8 a 18m, com tronco curto e cilíndrico, de 30 a $60 \mathrm{~cm}$ de diâmetro. Copa ampla e ramificada. Casca rugosa e descamante. Folhas compostas, bipinadas e opostas. Flores em capítulos globosos, púrpuros, suspensos em pedúnculos filiformes. Fruto legume achatado glabro, com sementes pequenas e achatadas dispostas em duas fileiras.

Copa ampla, aberta, com folhagem abuntante. Bela floração, com flores em capítulos purpúreos. Seus frutos são pequenos e leves. Recomendada para arborização de praças e parques.

\section{Astronium flraxinifolium Schott (Gonçalo Alves) - Anacardiaceae}

Árvore com porte de 25 a $30 \mathrm{~m}$, com tronco cilíndrico e reto de 60 a $80 \mathrm{~cm}$ de diâmetro. Copa ramificada, com perda total das folhas durante o inverno. Casca externa lisa, de cor cinza azulada, tanífera e resinífera. Folhas compostas, pinadas, com folíolos opostos. Flores pequeninas, brancas ou amarelas-esverdeadas, dispostas em panículas terminais ou axilares, compostas e amplas.Fruto drupa, leve, pequena, apiculada. As sementes verdadeiras não se separam do fruto.

Copa elevada e rala, com folhagem aberta, tronco resistente. Recomendada para arborização de praças e parques.

\section{Magonia glabrata St. Hil. (Tingui) - Sapindaceae}

Árvore com porte de 8 a 10m, com tronco de 20 a $30 \mathrm{~cm}$ de diâmetro. Copa aberta, com folhagem de aspecto rendilhado. Casca descamante, formada por pequenos círculos que se liberam. Folhas compostas paripenadas. Flores amarela-esverdeadas, odorantes, dispostas em grandes panículas. Fruto cápsula trigonada deiscente, castanho-avermelhado, contendo diversas longas e chentes Copa alta, pouco volumosa, com número reduzido de galhos, fuste elevado, folhagem aberta, bela floração, exalando odores aromatizantes. Espécie potencial para ser testada em calçadas laterais largas de vias públicas.

Hymenaea courbaril L. var. stilbocarpa (Hayne) Lee et Long. (Jatobá) Caesalpiniaceae

Árvore com porte de 15 a 25m, com tronco reto, cilíndrico, de até $1 \mathrm{~m}$ de diâmetro. Copa alta, muito esgalhada e frondosa. Casca externa cinzenta-clara, de lisa a áspera, com 
pequenos fissuras superficiais; casca interna rosada, com exsudação resinosa. Folhas alternas, compostas de dois folíolos brilhantes, médios, mais ou menos falciformes. Flores hermafroditas, brancas a cremes, reunidas em pequenas panículas terminais. Fruto legume indeiscente, meio cilíndrico, duro, pouco comprimido, de coloração marrom-brilhante, internamente revestido por polpa carnosa, farinácea, odor adocicado característico e comestível, com 2 a 8 sementes.

Copa alta, com bela folhagem verde-escura exibindo brilho intenso. Por outro lado, a floração não é muito vistosa. Fornece excelente sombra e serve à arborização de praças e parques.

\section{CONCLUSÕES}

A participação das árvores nativas na atual situação da arborização urbana de Teresina foi considerada boa, pois os resultados demonstram que a flora nativa presente na arborização de Teresina não se concentra apenas nos parques ambientais, mas tem significativa participação na arborização geral da cidade, principalmente nas praças e canteiros centrais das avenidas. No entanto, são necessários estudos e divulgação das espécies nativas com potencial para a arborização da cidade, principalmente para as calçadas laterais.

Dentre as dez espécies descritas e avaliadas, a maioria apresentou grande potencial para a arborização, devendo-se, no entanto, observar as restrições ao uso, principalmente devido ao grande porte da maioria das nativas.

\section{REFERÊNCIAS BIBLIOGRÁFICAS}

GOYA, C.R. Os jardins e a vegetação do espaço urbano: um patrimônio cultural. In: II Congresso Brasileiro de Arborização Urbana; V Encontro Nacional sobre Arborização Urbana. Anais... São Luiz: SBAU, 1994. p. 133-145.

LORENZI, H. Árvores brasileiras: manual de identificação e cultivo de plantas arbóreas nativas do Brasil. Nova Odessa: Plantarum, v.1, 1992. 352p.

LORENZI, H. Árvores brasileiras: manual de identificação e cultivo de plantas arbóreas nativas do Brasil. Nova Odessa: Plantarum, v.2, 1998. 352p.

MACHADO, R. B. Espécies nativas da arborização urbana de Teresina, Piauí. Recife: UFRPE, 2001.65f. Dissertação de Mestrado em Botânica-UFRPE. 
TERESINA, 1993. Teresina, aspectos e características, perfil 1993. Secretaria Municipal de Planejamento e Coordenação Geral. Teresina, 1993, 177p. 